\title{
Study of visually different areas in the Chinga iron meteorite fragment using Mössbauer spectroscopy with a high velocity resolution
}

\author{
M. I. Oshtrakh • M. V. Goryunov • V. I. Grokhovsky • \\ A. V. Chukin • A. K. Shtoltz • V. A. Semionkin
}

Published online: 1 November 2012

(C) Springer Science+Business Media Dordrecht 2012

\begin{abstract}
Visually different areas on the saw-cut surface of Chinga metal meteorite fragment were observed. Study of metal samples from these areas was carried out using scanning electron microscopy, X-ray diffraction and Mössbauer spectroscopy with a high velocity resolution. The obtained differences in Mössbauer parameters may be related to the differences in the microstructural $\mathrm{Fe}-\mathrm{Ni}$ phase composition.
\end{abstract}

Keywords Mössbauer spectroscopy with a high velocity resolution • $\mathrm{X}$-ray diffraction $\cdot$ Chinga metal meteorite $\cdot$ Metal phases

\section{Introduction}

Iron-nickel alloys formed in the extraterrestrial conditions and found in meteorites demonstrate some features in comparison with terrestrial analogues prepared for industrial needs. This may be a result of very slow cooling of melt alloys during

M. I. Oshtrakh $(\bowtie) \cdot$ M. V. Goryunov · V. I. Grokhovsky · V. A. Semionkin Department of Physical Techniques and Devices for Quality Control, Institute of Physics and Technology, Ural Federal University,

Ekaterinburg, 620002, Russian Federation

e-mail: oshtrakh@mail.utnet.ru,oshtrakh@gmail.com

M. I. Oshtrakh · M. V. Goryunov · V. I. Grokhovsky · V. A. Semionkin Department of Experimental Physics, Institute of Physics and Technology, Ural Federal University, Ekaterinburg, 620002, Russian Federation

A. V. Chukin

Department of Theoretical Physics and Applied Mathematics, Institute of Physics and Technology, Ural Federal University, Ekaterinburg, 620002, Russian Federation

\section{A. K. Shtoltz}

Department of Electrophysics, Institute of Physics and Technology, Ural Federal University, Ekaterinburg, 620002, Russian Federation 
Fig. 1 Different areas on the saw-cut surface of the Chinga fragment

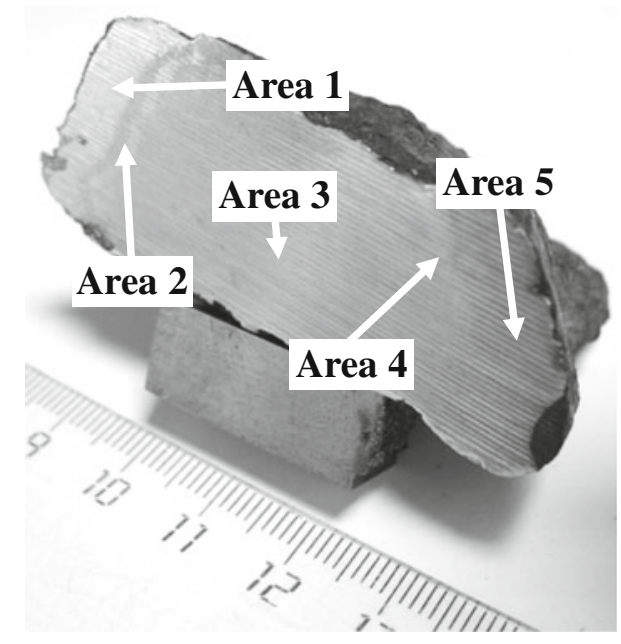

millions years. Moreover, extraterrestrial metal may be shocked and reheated. These conditions lead to peculiarities in the $\mathrm{Fe}-\mathrm{Ni}$ phase composition formation. Therefore, study of extraterrestrial $\mathrm{Fe}-\mathrm{Ni}$ alloys is of interest for development of terrestrial analogues with new features.

Chinga iron meteorite (ataxite IVB) consists of Fe-Ni alloy with about 17 at.\% of $\mathrm{Ni}$ and about 0.5 at.\% of Co. Previous analysis of Chinga metal demonstrated complicated structure with various phases such as $\alpha-\mathrm{Fe}(\mathrm{Ni}, \mathrm{Co}), \alpha_{2}-\mathrm{Fe}(\mathrm{Ni}, \mathrm{Co})$ and $\gamma-\mathrm{Fe}(\mathrm{Ni}, \mathrm{Co})$ and complex Mössbauer spectrum measured with a high velocity resolution [1]. In the present study we analyze a fragment of Chinga meteorite which sawcut surface showed several visually different areas using Mössbauer spectroscopy with a high velocity resolution and X-ray diffraction (XRD).

\section{Experimental}

The saw-cut surface of the Chinga meteorite fragment demonstrated several visually different areas which we denoted as area 1 up to area 5 (Fig. 1). The nature of these areas was unknown. Metal samples from each area except area 4, which was a very thin, were prepared in the form of powder in the same conditions. These powders were used for XRD and Mössbauer measurements. Samples for Mössbauer spectroscopy had a thickness within the limit of thin absorber.

Chinga metal samples from these areas were studied by XRD using XRD-7000 powder diffractometer (Shimadzu) operated at $40 \mathrm{kV}$ and $30 \mathrm{~mA}$ with Ni-filtered $\mathrm{CuK}_{\alpha}$ radiation in the $2 \Theta$ range of $40-120^{\circ}$. For detailed X-ray line profile analysis, step-scan data $\left(2 \Theta\right.$ step of $0.03^{\circ}$ and counting time of $\left.25 \mathrm{~s}\right)$ were recorded for these samples in the $2 \Theta$ range of $40-120^{\circ}$. The full profile Rietveld analysis was carried out with structural refinement with $\chi^{2}$ values in the range of $1.32-1.81$ and Bragg factor in the range of 0.61-0.81. The saw-cut surface of the fragment of Chinga meteorite was examined by scanning electron microscopy (SEM) with energy dispersion spectroscopy (EDS) using $\Sigma$ IGMA VP microscope (Carl Zeiss). Mössbauer spectra were measured in 4096 channels using an automated precision 

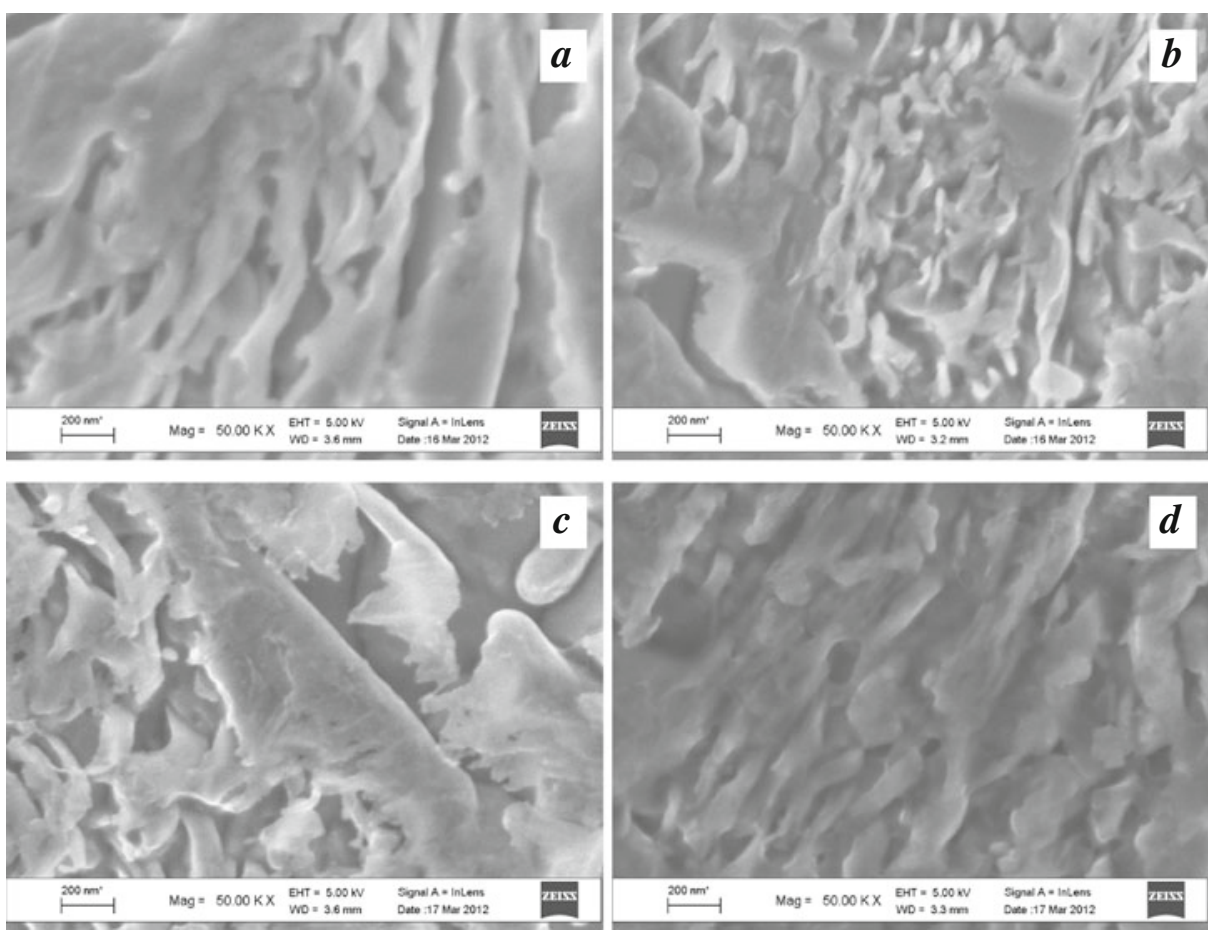

Fig. 2 Scanning electron microscopy images of Chinga metal areas 1 (a), 2 (b), 3 (c) and 5 (d)
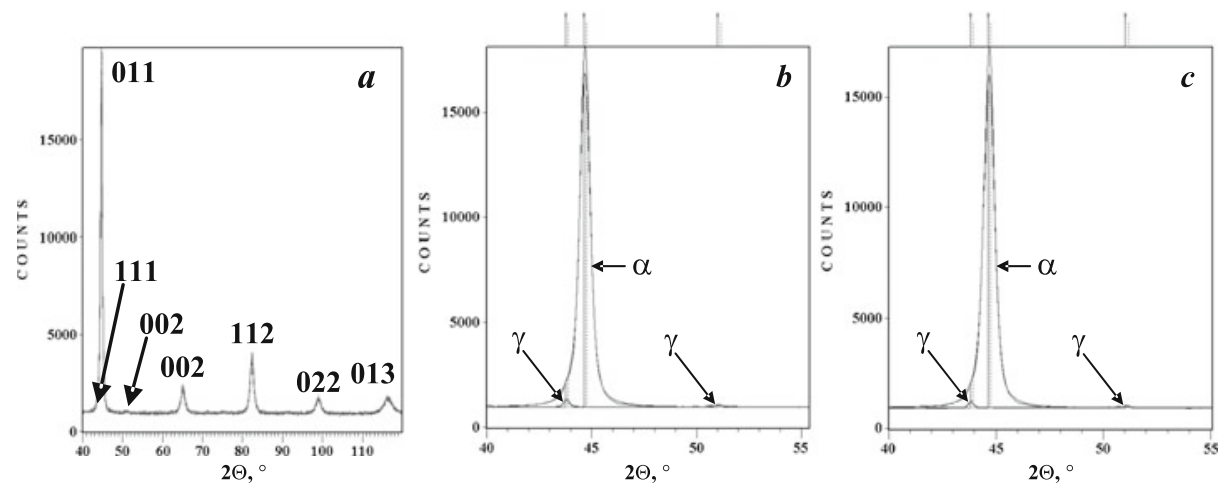

Fig. 3 X-ray diffraction patterns of the samples from areas 1, 2, 3 and 5 (a) and results of the full profile Rietveld analysis of the samples from area $1(\mathbf{b})$ and area $3(\mathbf{c}) . \alpha$ and $\gamma$ indicate $\alpha-\mathrm{Fe}(\mathrm{Ni}$, $\mathrm{Co})$ and $\gamma-\mathrm{Fe}(\mathrm{Ni}, \mathrm{Co})$ phases, respectively

Mössbauer spectrometric system, built on the base of the SM-2201 spectrometer with a high velocity resolution. The detailed characteristics of equipment and the spectra fit are given elsewhere [2,3]. 


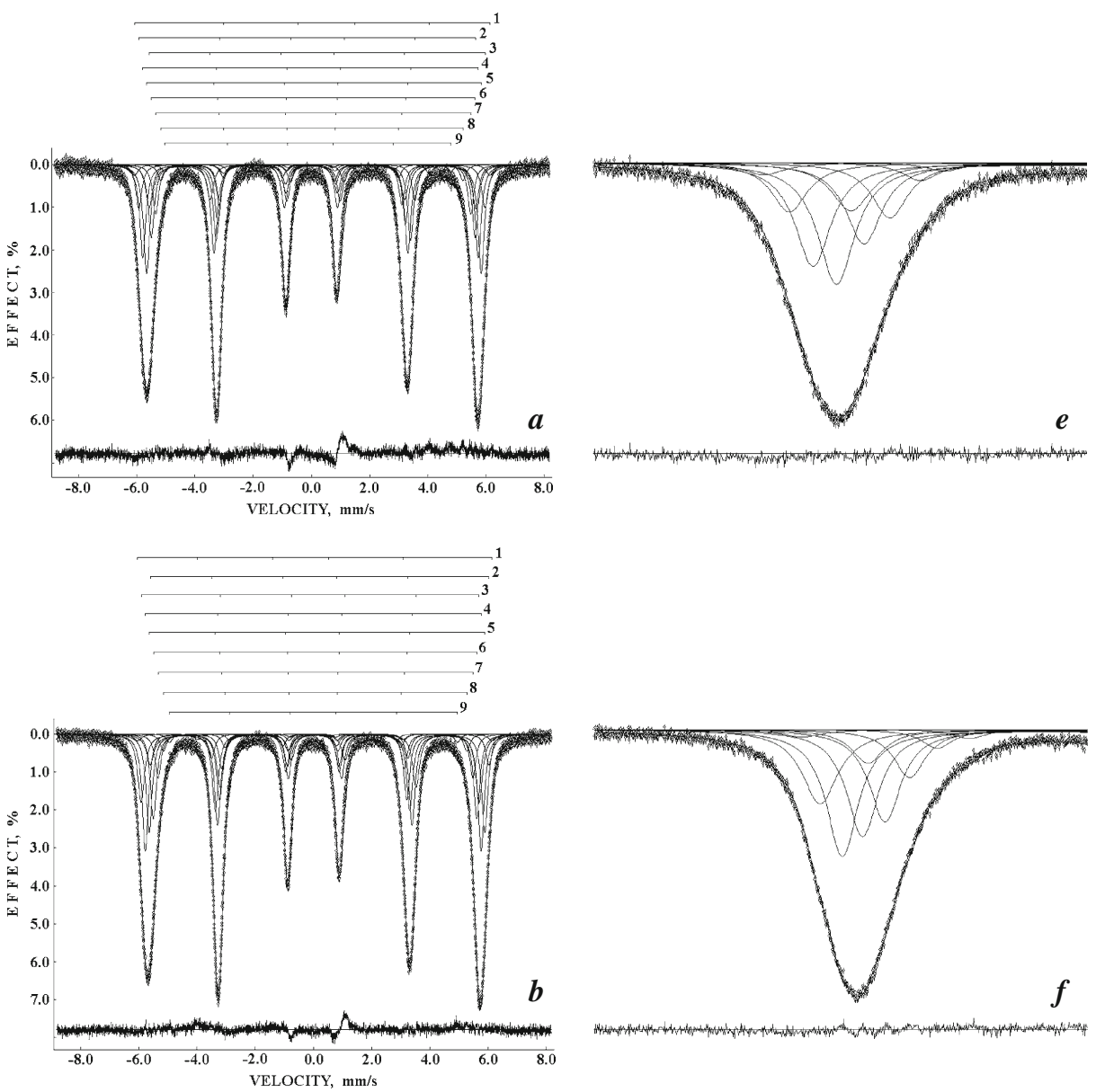

Fig. 4 Mössbauer spectra of Chinga metal from areas 1 (a), 2 (b), 3 (c) and 5 (d) and the shape of the most negative velocity peak in the spectra of Chinga metal from areas $1(\mathbf{e}), 2$ (f), 3 (g) and 5 (h). Indicated components are the result of the better fit. Differential spectra are shown below. $\mathrm{T}=295 \mathrm{~K}, 4096$ channels

\section{Results and discussion}

SEM images of areas 1, 2, 3 and 5 are shown in Fig. 2. These images were similar demonstrating complicated metal phase structure. However, it is possible to observe some variations in morphology and dimension of phase regions in different Chinga areas. EDS demonstrated that Ni concentration was in the range of $\sim 17.5-18.0$ at. \% for all areas. XRD patterns of the samples from areas 1, 2, 3 and 5 are shown in Fig. 3a. It was coincidence of diffraction peaks for all areas. The unit cell parameters were the same within the errors for each area. The tetragonal distortion observed on the basis of the line width was related to the presence of martensite $\alpha_{2}-\mathrm{Fe}(\mathrm{Ni}, \mathrm{Co})$ phase. However, the full profile Rietveld analysis showed small differences beyond 

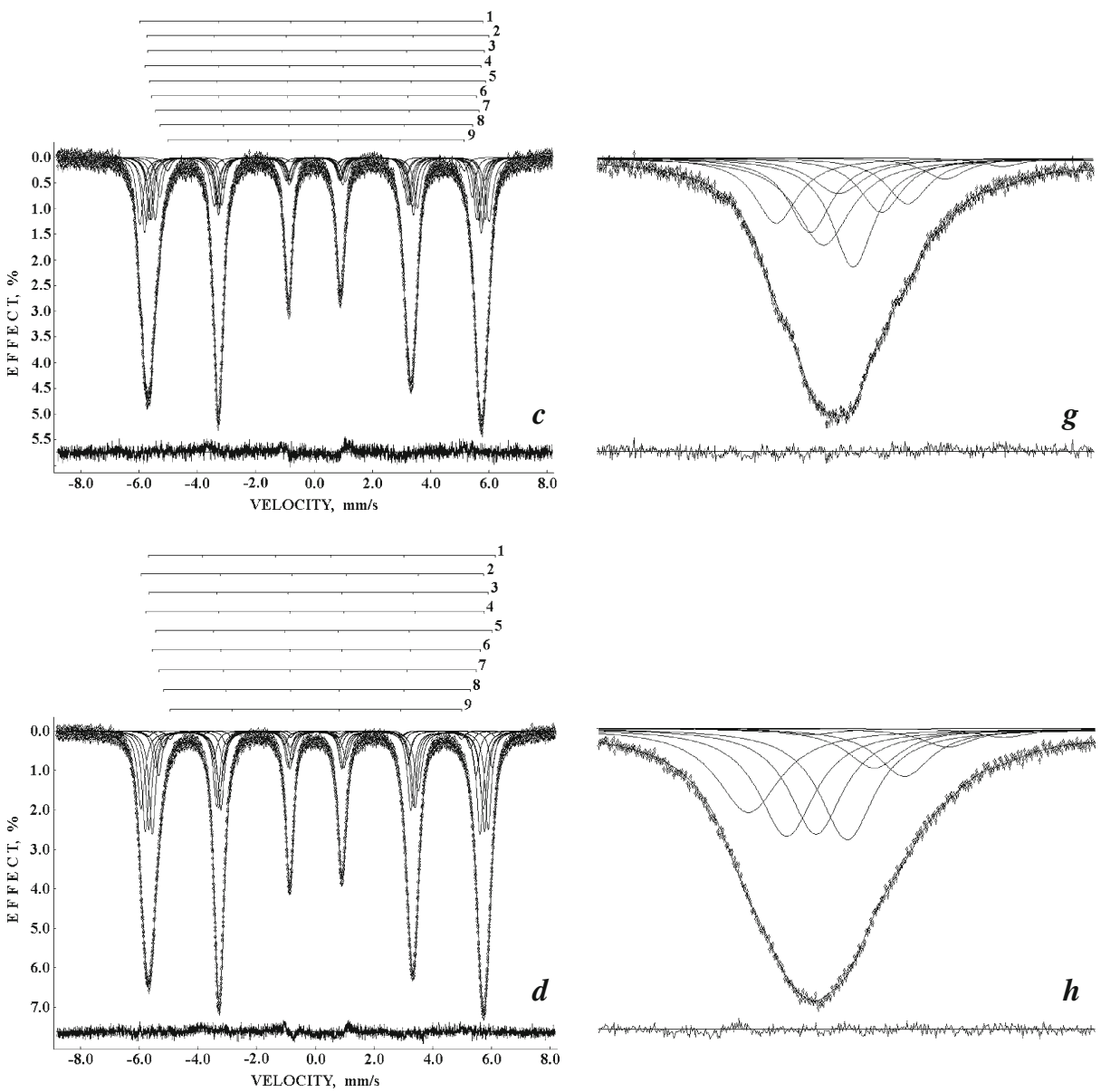

Fig. 4 (continued)

the error in the presence of $\gamma-\mathrm{Fe}(\mathrm{Ni}, \mathrm{Co})$ phase in addition to $\alpha$ phase (see Fig. 3b, c) in studied areas: $2.6 \%(1), 1.5 \%(2), 1.8 \%(3)$ and $2.3 \%(5)$.

Mössbauer spectra of Chinga metal from areas 1, 2, 3 and 5 measured at room temperature in 4096 channels are shown in Fig. 4a-d. These spectra are asymmetric six-line patterns. To reach the better fit we used up to nine magnetic sextets because in the fits with less number of components differential spectra and statistical criterion $\chi^{2}$ were not good. It was interesting to observe the differences in these spectra fit. Moreover, the shape of the first peak (at about $-6.0 \mathrm{~mm} / \mathrm{s}$ ) in these spectra appeared to be slightly different, especially, for the metal from area 3 (see Fig. 4e-h).

Mössbauer parameters obtained for spectral components appeared to be different for different Chinga metal areas. It is clearly seen in comparison of the histograms for the spectral components obtained for Mössbauer spectra of Chinga metal areas 1, 2, 3 and 5 (see Fig. 5). This result showed the differences for Chinga metal areas 

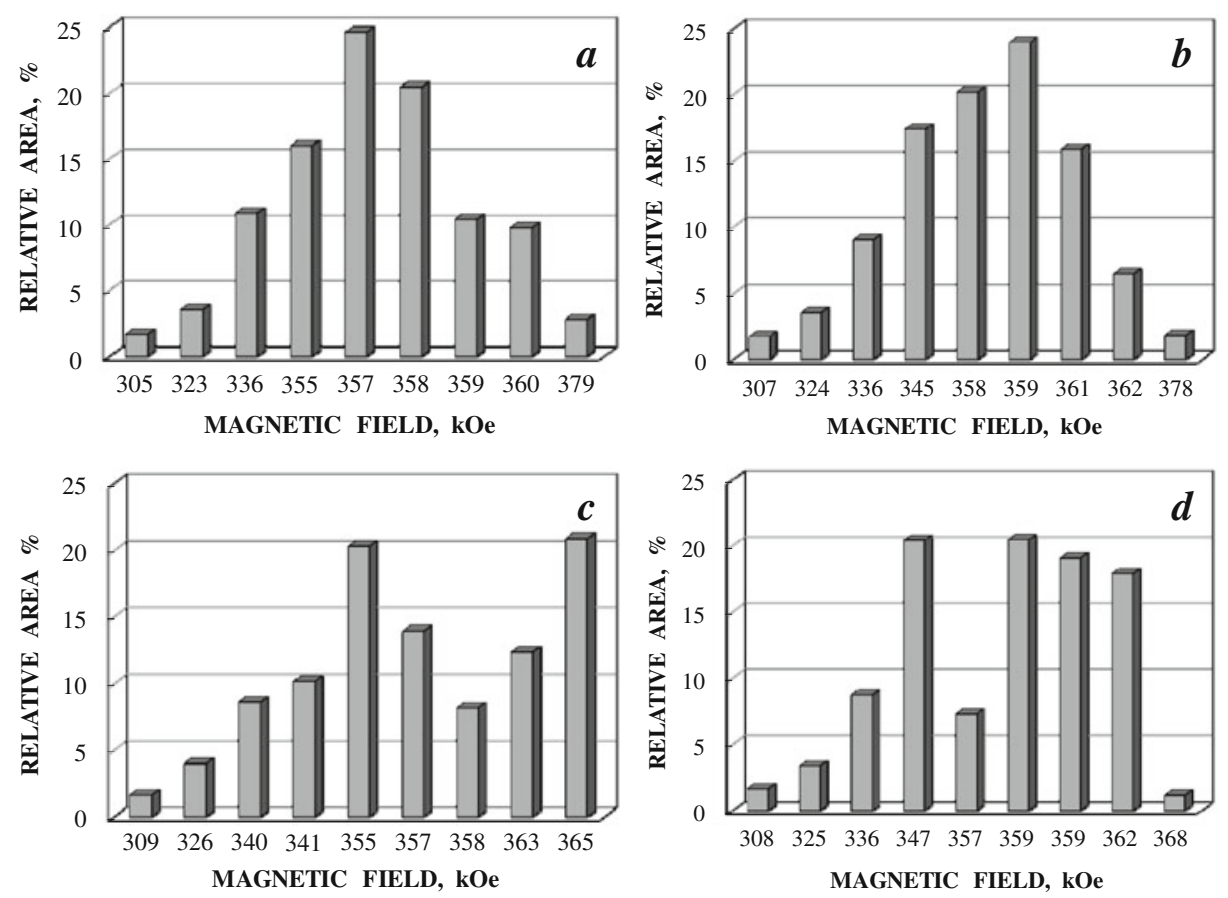

Fig. 5 Histograms of the relative areas of magnetic sextets obtained from the better fit of Mössbauer spectra of Chinga metal from areas 1 (a), 2 (b), 3 (c) and 5 (d)

1, 2, 3 and 5. It is possible that there is variation of the Fe-Ni phase composition and local $\mathrm{Ni}$ concentration in metal local microstructures.

\section{Conclusion}

Study of visually different areas observed on the saw-cut surface of the Chinga metal fragment using scanning electron microscopy, X-ray diffraction and Mössbauer spectroscopy was carried out. X-ray diffraction showed the presence of $\alpha-(\mathrm{Fe}, \mathrm{Ni})$ and $\alpha_{2}-(\mathrm{Fe}, \mathrm{Ni})$ phases and small variation of the $\gamma-(\mathrm{Fe}, \mathrm{Ni})$ phase in studied Chinga metal areas. Mössbauer spectra demonstrated some differences in the spectral line shapes and results of the better fit using nine magnetic sextets. Differences in Mössbauer parameters for the spectral components may be related to the differences in the Fe-Ni phase composition and local Ni concentration in Chinga metal local microstructures. However, the nature of these areas difference is not clear yet and further investigations are required.

Acknowledgements This work was supported in part by the basic financing from the Ministry of Science and Education of Russian Federation and the Federal Grant-in-Aid Program "Human Capital for Science and Education in Innovative Russia" (Governmental Contracts No 14.740.11.1006 and No. P1154). 


\section{References}

1. Oshtrakh, M.I., Grokhovsky, V.I., Abramova, N.V., Semionkin, V.A., Milder, O.B.: Hyperfine Interact. 190, 135 (2009)

2. Oshtrakh, M.I., Semionkin, V.A.: Spectrochim. Acta, A Mol. Biomol. Spectrosc. (2012). doi:10.1016/j.saa.2012.03.020

3. Semionkin, V.A., Oshtrakh, M.I., Milder, O.B., Novikov, E.G.: Bull. Russ. Acad. Sci., Phys. 74, 416 (2010) 